\title{
The role of enemy release, tolerance and resistance in plant invasions: linking damage to performance
}

\author{
Young Jin Chun, ${ }^{1 *}$ Mark van \\ Kleunen ${ }^{2}$ and Wayne Dawson ${ }^{2}$ \\ 'INRA, UMR 1210 Biologie et \\ Gestion des Adventices, 17 Rue \\ Sully, BP 86510, F-21065 Dijon \\ Cedex, France \\ ${ }^{2}$ Institute of Plant Sciences, \\ University of Bern, \\ Altenbergrain 21, CH-3013 Bern, \\ Switzerland \\ *Correspondence and present \\ address: Bio-Evaluation Center, \\ KRIBB, 685-1 Yangcheong-ri, \\ Ochang-eup, Cheongwon, \\ Chungbuk 363-883, Republic of \\ Korea \\ E-mail: youngjinchun@ \\ gmail.com
}

\begin{abstract}
An explanation for successful invasion is that invasive alien species sustain less pressure from natural enemies than co-occurring native species. Using meta-analysis, we examined whether invasive species: (1) incur less damage, (2) exhibit better performance in the presence of enemies, and (3) tolerate damage more than native species. Invasive alien species did not incur less damage than native species overall. The performance of invasive alien species was reduced compared to natives in the presence of enemies, indicating the invasive alien species were less tolerant to damage than native species. However, there was no overall difference in performance of invasive alien and native species with enemies present. The damage and degree of reduction in performance of invasive alien relative to native species did not depend on relatedness to natives. Our results suggest aliens may not always experience enemy release, and enemy release may not always result in greater plant performance.
\end{abstract}

\section{Keywords}

Biotic resistance, congener, enemy release, exotic species, invasive species, meta-analysis, natural enemies, non-indigenous species, taxonomic relatedness, tolerance.

\section{INTRODUCTION}

What determines invasiveness of alien species in their introduced range is the primary question in invasion biology (Sakai et al. 2001). An intuitively attractive and popular hypothesis is that the high abundance and wide distribution of invasive alien species is driven by release from natural enemies in the introduced range (i.e. the enemy-release hypothesis, Elton 1958; Keane \& Crawley 2002). Enemy release is viewed as an important factor explaining invasions, and is frequently used as justification for the introduction of natural enemies as bio-control agents of invasive alien species (Hajek 2004). However, despite evidence that alien plants frequently have fewer natural enemies, such as herbivores (Liu \& Stiling 2006) and pathogens (Mitchell \& Power 2003; van Kleunen \& Fischer 2009) in their introduced than in their native ranges, it is still not clear whether reduced enemy attack leads to improved alien plant performance relative to native plant species and subsequently to invasion (e.g. Colautti et al. 2004; van Kleunen \& Fischer 2009).

Even when alien species are released from natural enemies in their introduced compared to their native ranges, this might not give them an advantage over native species when the latter also incur little damage by enemies. Studies that compare enemy loads and damage between invasive alien and native species are less equivocal than studies comparing populations of invasive species in their native and introduced ranges (Colautti et al. 2004). As we point out in this paper, differences in damage may not necessarily translate into differences in performance between invasive alien and native species, and some plants may be able to tolerate damage and maintain performance due to compensatory growth (Strauss \& Agrawal 1999). Therefore, studies should not only assess damage but also the consequences for plant performance.

In this study, we first employ a meta-analytical approach to review studies that compared enemy damage between invasive alien and native species. Then we develop a framework for how to test whether enemy release affects relative performance of invasive alien and native species. Finally, we develop a framework to test the importance of tolerance and enemy release. We do this by linking the damage incurred by invasive alien and native species in the presence of natural enemies to the difference in relative performance when grown in the absence and presence of natural enemies. 


\section{DAMAGE INCURRED BY INVASIVE AND NATIVE SPECIES}

Previous reviews of damage incurred by invasive alien and native species have been equivocal with regard to their support of the enemy-release hypothesis. A review by Colautti et al. (2004) revealed that only a few studies found evidence that invasive alien species incur less damage than native species. Liu \& Stiling (2006) confirmed this finding when they used the same vote-counting approach. However, when Liu \& Stiling (2006) conducted a meta-analysis, which accounts for differences in sample sizes and variance within and between studies, they found that invasive alien species incurred significantly less herbivory damage than native species. Similarly, a meta-analysis of Hawkes (2007) found that invasive species had significantly lower levels of pathogen infestation than native species had, and that there was a non-significant trend for lower herbivory damage on invasive alien species than on native species. Although these previous meta-analyses included $>20$ pairs of invasive alien and native species, they came from a limited number of studies, and variation among studies was not accounted for in the analyses. Consequently, they may have overestimated the generality of differences in damage between invasive alien and native species.

The enemy damage incurred by invasive alien species may depend on their phylogenetic/taxonomic relatedness to native species (Mack 1996; Mitchell et al. 2006). On one hand, alien species are likely to share enemies with closely related native species, and thus alien species with closely related native species in the introduced range might incur relatively more damage than alien species without closely related native species (Dawson et al. 2009; Hill \& Kotanen 2009; Pearse \& Hipp 2009). On the other hand, alien species are likely to have similar defense mechanisms to closely related native species, and thus alien species with closely related native species might incur relatively less damage than alien species without closely related native species (Parker et al. 2006; Ricciardi \& Ward 2006; Brandt et al. 2009). The direction of the relationship between enemy damage on aliens and relatedness to native species remains largely unresolved.

To test whether invasive alien species generally incur less enemy damage than native species, and whether this depends on taxonomic relatedness of the alien invasive and native species, we conducted a meta-analysis of published studies (see Appendix S1 for details on the methods). Briefly, we calculated effect sizes (log-response ratios), which quantify the damage on invasive alien species relative to the damage on native species, and their variances for differences in enemy damage between invasive alien and native plant species. In total, our analysis included 109 relative-damage effect sizes for 72 pairs of invasive alien and native species from 19 published studies (Appendices S3 \& S5).
Overall, when we treated effect sizes as independent data points and species pairs as random effects, irrespective of whether some pairs came from the same study, we found that invasive alien species incurred significantly less damage than native species (grand mean of the effect size $=-0.356$; $95 \% \mathrm{CI}=-0.676,-0.035)$. This confirms the findings of previous meta-analyses (Liu \& Stiling 2006; Hawkes 2007). However, when we accounted for differences in effect sizes between studies and between species pairs within studies, the difference in damage between invasive alien and native species was not significant anymore (grand mean of the effect size $=-0.381 ; \quad 95 \% \quad C I=-0.920,0.158)$. This suggests that overall there is still no consistent evidence that invasive alien species incur less damage than native species, once interstudy variation in effect sizes is accounted for.

We also tested whether damage on invasive alien relative to damage on native species differed between congeneric and non-congeneric species pairs (i.e. whether it depends on taxonomic relatedness), and whether it depended on if the experiment was conducted in the greenhouse or field (study type). There were no significant effects of taxonomic relatedness on relative damage (Fig. 1, Table 1). Interestingly, we detected a weak but significant difference in



Figure 1 Relative damage to invasive alien species compared to congeneric and non-congeneric native species measured under field and greenhouse conditions. Symbols show mean effect sizes $\pm 95 \%$ confidence intervals. The numbers of species pairs are given in parentheses. A confidence interval overlapping zero represents no overall difference in damage between invasive alien and native species. A positive confidence interval indicates that invasive alien species receive greater damage, whilst negative indicates that native species incur greater damage. 
Table 1 Summary statistics of model testing for differences in effect size of relative damage on invasive alien vs. native species according to study type (field vs. greenhouse) and taxonomic relatedness to the native comparator (congeneric vs. non-congeneric)

\begin{tabular}{|c|c|c|c|}
\hline Variable & d.f. & $F$ & $P$ \\
\hline Intercept & 1,56 & 2.041 & 0.159 \\
\hline Study type & 1,31 & 3.687 & 0.064 \\
\hline Taxonomic relatedness & 1,56 & 0.092 & 0.762 \\
\hline Study type $\times$ taxonomic relatedness & 1,31 & 0.276 & 0.603 \\
\hline Random effects & & Variance & \\
\hline Study & & 0.621 & \\
\hline Species pair & & $1.534 \mathrm{e}-11$ & \\
\hline Individual effect size & & 2.230 & \\
\hline Residual & & $4.057 \mathrm{e}-11$ & \\
\hline
\end{tabular}

relative damage depending on the type of study (Table 1), with invasive alien species incurring relatively less damage than native species in field studies compared to greenhouse experiments (Fig. 1). This result is in accordance with a hypothesis that some invasive alien species may flourish when natural enemies do not recognize them as a suitable food source outside in the field, but that these natural enemies will feed on them when they are enclosed with the plants (Siemann \& Rogers 2003). Similarly, Lankau et al. (2004) reported that grasshoppers do not actively consume invasive Sapium sebiferum (recently renamed Triadica sebifera) in open field conditions but that they feed on S. sebiferum to a greater extent than on native Celtis laevigata in enclosed conditions. The fact that native enemies can attack invasive alien species when enclosed suggests that ultimately, given sufficient time, these enemies might also start to attack the invasive alien plants in the field. Indeed, the meta-analysis of Hawkes (2007) indicated that invasive alien plants may accumulate enemies over time. Nevertheless, our results indicate that assessment of damage incurred by invasive alien and native species under experimental conditions in the greenhouse may not be representative for damage incurred under natural conditions. Overall, there was still little evidence that invasive alien species incurred less damage than native species under field conditions.

\section{RELATIVE PERFORMANCE OF INVASIVE AND NATIVE SPECIES IN THE ABSENCE AND PRESENCE OF ENEMIES}

Although previous meta-analyses showed significantly more enemy damage on native than on invasive alien species (Liu \& Stiling 2006; Hawkes 2007), the differences in damage are frequently very small (e.g. Carpenter \& Cappuccino 2005). Therefore, the question emerges whether such small differences in damage have major consequences. Some studies on bio-control of invasive alien species indicate that extremely high damage levels may be required to control the plant species (Noble \& Weiss 1989; Parker 2000). Thus, instead of testing for differences in damage, it would be more informative to test whether performance of invasive alien species is suppressed to a lesser extent by natural enemies than performance of co-occurring native species in the introduced range (Maron \& Vilà 2001; Keane \& Crawley 2002; Colautti et al. 2004; Liu \& Stiling 2006; Hawkes 2007). Clearly, the latter requires studies that assess performance of invasive alien and native species in the presence and absence of natural enemies.

Under the assumption that in the absence of enemies invasive alien species usually have higher performance than native species (van Kleunen et al. 2010), and that performance of species is reduced by enemies, there are potentially four different outcomes for invader performance in the presence of enemies (Fig. 2). First, performance of invasive alien species might be reduced less strongly than the performance of native species, and as a consequence the relative performance of the invasive alien over the native species increases (Fig. 2a). Second, performance of invasive alien and native species might be reduced to the same degree, and as a consequence the relative performance of the invasive alien over the native species remains the same (Fig. 2b). Third, performance of invasive alien species might be reduced more strongly than the performance of native species, and as a result the relative performance of the invasive alien over the native species decreases (Fig. 2c). Fourth, performance of the invasive alien species might decrease to such a degree that its relative performance becomes negative in the presence of enemies (Fig. 2d). Enemy release could have an additive effect on existing performance differences between native and invasive alien species, or it could act singularly, providing a performance advantage for invasive alien species which would otherwise exhibit a similar performance to native species in the absence of enemies.

To test whether relative performance of invasive alien species over native species generally increases in the presence of enemies, which is predicted by the enemyrelease hypothesis, and whether this depends on taxonomic relatedness of the alien invasive and native species, we conducted a second meta-analysis of published studies (see Appendix S1 for details on the methods). We calculated effect sizes (log-response ratios) and their variances for differences in performance between invasive alien and native plant species both in the absence and presence of enemies (i.e. the performance of invasive alien species was expressed relative to the performance of native species). In total, our 


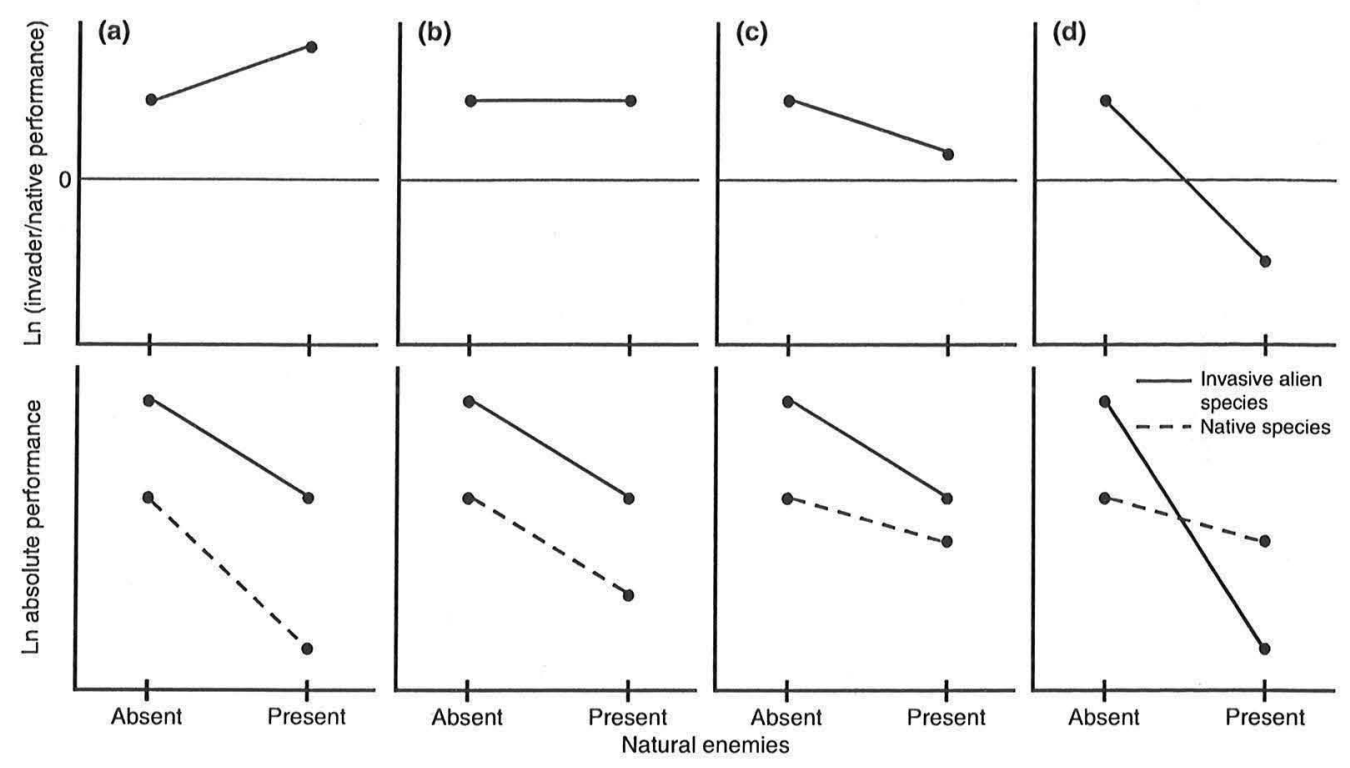

Figure 2 Potential changes in absolute performance (lower panels) and relative performance (upper panels) of invasive alien over native species in the absence and presence of enemies. Depending on the magnitudes of the enemy impact on absolute performance of invasive alien and native species, the relative performance of invasive alien over native species may (a) increase, (b) remain the same, or (c, d) decrease when plants are exposed to enemies. The latter could be to such an extent that relative performance of invasive alien over native species changes from positive in the absence of enemies to negative in the presence of enemies (d). Although we depicted the situation in which invasive alien species always have a higher performance than the native species in the absence of natural enemies, this is not necessarily the case. In the other cases, the patterns of increasing, unchanging or decreasing relative performance in response to enemy exposure should still be as depicted in $(\mathrm{a}-\mathrm{d})$.

analysis included 35 pairs of invasive alien and native species from nine published studies (Appendices S4 \& S5).

We first examined the overall relative performance of invasive alien species compared to native species with natural enemies excluded. The overall mean relative performance was positive, but not significantly greater than zero (grand mean $=0.644 ; 95 \% \mathrm{CI}=-0.391,1.679$ ), indicating that, on average, invasive species do not outperform native species in this data set. Then, to assess the impact of natural enemies on the relative performance of invasive species compared to native species, we explored two models, one with the factor 'natural enemies' (absence vs. presence; i.e. enemies excluded or not) only, and the other including in addition the factor 'taxonomic relatedness' (congeneric vs. non-congeneric pairs) and its interaction with 'natural enemies'. The first model indicated that relative performance was significantly reduced by the presence of natural enemies, compared to when they were excluded (Fig. 3a, Table 2). However, 95\% CIs of relative performance in the presence of enemies still overlapped zero (Fig. 3a), indicating that the performance of invasive alien species did not decline significantly below that of the native species, when natural enemies were present. The second model also revealed a significant decrease in relative performance of invasive alien species in the presence of enemies, whilst there was no difference in relative performance between congeneric and non-congeneric pairs and no interaction between 'natural enemies' and 'taxonomic relatedness' (Table 2). These results are thus closest to the scenarios presented in Fig. 2c,d, and indicate that invasive alien species do not have an advantage over native species in the presence of enemies, rather, invasive alien species tend towards having a disadvantage compared to native species. Therefore, our results contradict the predictions of the enemy-release hypothesis, questioning the role of natural enemies in suppressing native species and facilitating invasive alien species.

\section{ENEMY RELEASE, TOLERANCE AND RESISTANCE IN RELATION TO INVADER PERFORMANCE}

Plant performance in the presence of natural enemies is likely to be determined by the amount of damage imposed by natural enemies, which is determined by their resistance to enemies and by their tolerance to damage (Marquis 1992). Whilst resistance is related to plant traits (e.g. 
Figure 3 (a) Overall mean relative performance of invasive alien species compared to native species in the absence and presence of enemies. (b) Comparison of relative performance between invasive alien species congeneric or non-congeneric to native species. Negative numbers indicate worse performance, and positive numbers better performance of invasive alien species relative to native species. Symbols show mean effect sizes $\pm 95 \%$ confidence intervals. The numbers of species pairs are given in parentheses.

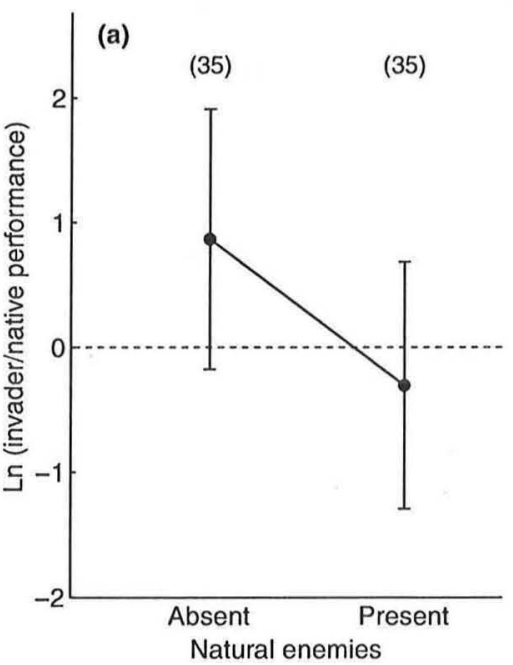

Table 2 Summary statistics of two models testing for differences in effect size of relative performance of invasive alien vs. native species as a function of natural enemies (presence vs. absence), and taxonomic relatedness to the native species comparator (congeneric or non-congeneric)

\begin{tabular}{|c|c|c|c|}
\hline Variable & d.f. & $F$ & $P$ \\
\hline \multicolumn{4}{|l|}{ Model 1} \\
\hline Intercept & 1,34 & 0.139 & 0.711 \\
\hline Natural enemies & 1,34 & 9.611 & 0.004 \\
\hline Random effects & & \multicolumn{2}{|l|}{ Variance } \\
\hline Species pair within study & & 4.981 & \\
\hline Individual effect size & & $1.670 \mathrm{e}-8$ & \\
\hline Residual & & 0.373 & \\
\hline \multicolumn{4}{|l|}{ Model 2} \\
\hline Intercept & 1,33 & 0.136 & 0.714 \\
\hline Natural enemies & 1,33 & 9.593 & 0.004 \\
\hline Taxonomic relatedness & 1,33 & 0.337 & 0.566 \\
\hline Natural enemies $\times$ taxonomic relatedness & 1,33 & 1.073 & 0.308 \\
\hline Random effects & & \multicolumn{2}{|l|}{ Variance } \\
\hline Species pair within study & & 5.091 & \\
\hline Individual effect size & & $3.785 e-8$ & \\
\hline Residual & & 0.373 & \\
\hline
\end{tabular}

chemical and mechanical defenses) that reduce the preference and performance of natural enemies, tolerance is the ability to compensate for the effect of damage by regrowth after damage (Strauss \& Agrawal 1999; MüllerSchärer et al. 2004; Stastny et al. 2005). Given that many invasive alien species tend to grow faster than native species (van Kleunen et al. 2010), one might expect that they would have a greater capacity of re-growth after damage, and thus to have a higher tolerance to damage
(Strauss \& Agrawal 1999; Ashton \& Lerdau 2008). However, to the best of our knowledge, this hypothesis has been rarely tested (but see Ashton \& Lerdau 2008).

The importance of tolerance to damage for invasiveness can only be assessed, if we combine data on damage of invasive alien and native species in the presence of enemies with data on how the relative performance of invasive alien over native species depends on whether the plants are grown in the absence or presence of enemies (Box 1). The results of our meta-analyses showed that whilst there is a non-significant trend of invasive alien species incurring less damage than native species, invasive alien species suffered a decrease in performance relative to native species when natural enemies are present. This could suggest that invasive alien plants may have a lower tolerance to enemy damage than native plant species. However, because many of the species pairs included in the meta-analysis on damage were not included in the meta-analysis on relative performance in the presence and absence of enemies and vice versa, results of both meta-analyses cannot be directly compared. Therefore, we compared relative damage and difference in relative performance of invasive alien species with and without enemies for a subset of studies that had damage and performance effect sizes available for the same species pairs. In addition, only damage data for field experiments were used, as performance measures were only obtained from plants growing in the field.

In total, six studies contained both relative damage and relative performance data for 15 species pairs. When more than one relative-damage effect size was available per pair, we calculated a weighted mean effect size using the associated variances. When the effect sizes of relative damage on invasive alien vs. native species were plotted 
Box 1 Hypothetical frameworks on the relative damage and performance of invasive alien species compared to native species
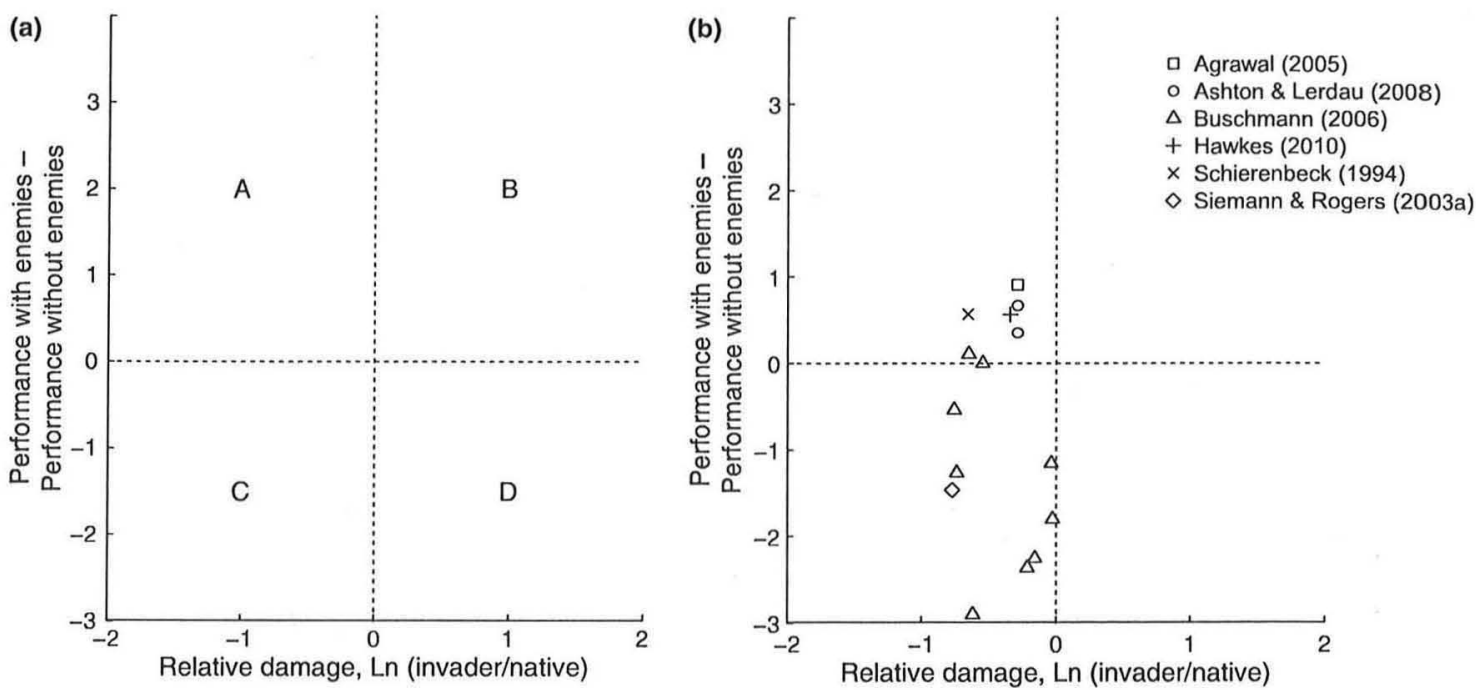

(a) From relationships between relative damage incurred by invasive alien compared to native species, and the difference in relative performance of invasive alien over native species between plants grown in the absence and presence of enemies, we can infer whether enemy release or tolerance to damage are key to the success of invasive alien over native species. Points falling only in quadrant A would represent invasive alien species experiencing relatively less damage compared to native species (when enemies are present), and the difference in relative performance compared to natives when enemies are present vs. when they are absent is positive. This means that invasive alien species have a greater advantage over native species when enemies are present, because native species suffer more damage and a subsequent decrease in performance than the invasive species; i.e. there is support for the enemy-release hypothesis or for greater resistance of invasive alien species to enemy attack. Points in Quadrant B would represent invasive alien species incurring more damage than native species, but the difference between relative performance with and without enemies present is still positive. This would thus indicate that invaders are much more tolerant of enemy damage than native species, and are able to maintain a performance advantage over native species by compensating for damage by enemies. Points in Quadrant $\mathrm{C}$ would represent invasive alien species having a performance worse than native species when enemies are present as opposed to when they are absent, even when the invasive alien species incur less damage than the native species. This indicates that the native species, and not the invasive alien species, are more able to compensate for enemy losses and would outcompete invaders if they were to cooccur with high natural enemy levels. Finally, points in Quadrant $\mathrm{D}$ would represent invasive alien species incurring more damage than native species, and subsequently also have a decrease in relative performance over native species when enemies are present compared to when they are absent. Native species, instead of invasive alien species, are more resistant to natural enemies, and would again outcompete invasive alien species if they were to co-occur.

Thus, points only in Quadrant A would offer unanimous support for the enemy-release hypothesis. If points occur in Quadrants $A-B$, then on average there are no differences in enemy damage between invasive alien and native species, but invasive alien species outperform native species with enemies present either through tolerance, resistance or enemy release. Points scattered in Quadrants A-C would indicate that, whilst invasive alien species suffer less damage than native species, this does not always translate to greater performance than native species; i.e. the enemy-release hypothesis does not apply to all invasive alien species. Similarly, points in Quadrants B-D would indicate that some invasive alien species are more tolerant of enemies than native species leading to greater performance of the invasive alien species, but on average there is no difference in performance between invasive alien and native species. Finally, points straddling Quadrants C-D would suggest that invasive alien species never have greater performance than native species regardless of relative damage, and that invasive alien species should not be able to co-occur with the native species considered. Points scattered across all quadrants would suggest complete idiosyncrasy among invasive alien species. 


\section{Box 1 continued}

To illustrate this conceptual framework, we investigated the subset of studies already used that included data on relative damage of invaders vs. natives, and relative performance of invaders vs. natives in the absence and presences of enemies. This yielded six studies and 15 pairs of invasive alien and native species (b). We only used damage data recorded from field experiments in these studies, and calculated weighted averages (using the associated variances) of relative damage values where more than one value was available per species pair. Whilst this is a small sample size, all invasive alien species in these studies incurred relatively less damage than native species, but only six invasive alien species had greater performance than native species when enemies were present compared to when enemies were absent (b). This indicates an A-C scenario, where enemy release or resistance to attack may be responsible for success of some invasive alien species over native species, but in more than half of the cases, other factors must be responsible for success of the invasive alien species.

against the difference in effect size of invader relative performance with and without enemies, invasive alien species incurred less damage than native species in all species pairs (Box 1). However, only six of the 15 invasive alien species experienced an increase in plant performance relative to native species when enemies were present. Whilst the number of species pairs is limited, the results from these studies suggest that lower enemy damage of invasive alien species compared to native species does not always result in a performance advantage of invasive alien over native species. Thus, native species might be more tolerant to damage than invasive alien species, and enemy release and resistance to natural enemies may influence invasion success of some but not all alien species.

\section{DISCUSSION AND CONCLUSIONS}

The enemy-release hypothesis is one of the most popular hypotheses in invasion biology (Hierro et al. 2005; Inderjit et al. 2005). However, our meta-analyses did not reveal consistent evidence that invasive alien species incur less damage than native species, once interstudy variation in effect sizes is accounted for. Moreover, we found that relative performance of invasive alien over native species decreased rather than increased in response to the presence of natural enemies. This indicates that there is little support that enemy release is the major driver of plant invasions.

One potential reason for the lack of support for the enemy-release hypothesis is that the number of studies that assessed both enemy damage of invasive alien and native species and their performance in the presence and absence of enemies is still very low. Moreover, in our meta-analyses, heterogeneity in effect sizes was likely to be large because studies used different measures of damage and performance, considered different enemies, and were conducted in different growing seasons. Therefore, we explored which class variables are most likely to explain data heterogeneity using $Q$ statistics in the program MetaWin (Rosenberg et al. 2000; Appendix S2). Effect sizes of relative performance of invasive alien over native species did not differ significantly between any class variables, whilst effect sizes of relative damage varied significantly among studies, types of enemy considered and growing season. Some of the studies that we included in our meta-analyses also reported that enemy damage significantly varied among species (Blaney \& Kotanen 2001; Agrawal et al. 2005; Ashton \& Lerdau 2008; Caño et al. 2009), natural enemies (Parker \& Gilbert 2007; Caño et al. 2009; Hawkes et al. 2010) and habitats (Blaney \& Kotanen 2001; Siemann \& Rogers 2003; Knapp et al. 2008). It is likely that such differences among attempts to test the enemy-release hypothesis contribute to the lack of consensus among study results.

A bias towards generalist enemies in the collected studies may affect the damage and tolerance of invasive alien species. Although most studies tested enemy release in a common garden setup in the field where generalists and specialists coexist, some studies exclusively focused on generalist enemies (mammals, mollusks and crayfishes; Appendices S3, S4). Together with this, the relatively small number of studies available prevented a thorough assessment of the relative levels of enemy release from specialist and generalist enemies. Similarly, the low number of studies used may have also limited power to detect significant differences in damage between native and alien species, when study was included as a random effect. Furthermore, a limitation of enemy-release studies comparing an invasive alien species to one native species is that invasive alien species potentially compete with multiple native species in a host community. Thus, assessing the performance benefit of invasive alien relative to native species due to enemy release at a community level requires comparisons with multiple native species that the alien is likely to encounter. Due to plant defense/growth tradeoffs (Herms \& Mattson 1992), we might expect relative performance of the invasive alien species to vary according to the functional traits of native comparator species linked to growth and defense.

A better understanding of the importance of enemy release for plant invasions may be achieved by extending 
both the spatial and temporal scales of experiments. This would allow us to assess the enemy impact across a broad range of habitats and climatic conditions that vary among years (Hawkes 2007). Moreover, it would allow us to test whether small levels of enemy release across years result in major cumulative effects on plant performance, and to test whether certain years of major enemy release provide windows-of-opportunity for invasive alien plants (Agrawal et al. 2005). Depending on years or growing seasons, the relative damage to introduced and native species may be affected even in an inverse direction (Agrawal \& Kotanen 2003; Agrawal et al. 2005; Parker \& Gilbert 2007; Hawkes et al. 2010). Therefore, other biotic or abiotic factors (e.g. competitors, mutualists, resource availability and disturbance) may contribute to, or mask, the general differences in the effects of natural enemies (Colautti et al. 2004; Blumenthal 2006; Mitchell et al. 2006). In addition, it has been suggested that enemy impact may strongly depend on the life history of plants (Louda \& Potvin 1995). Short-lived plants that rely on current seed production for regeneration are most vulnerable to herbivory, which reduces seed production, whereas long-lived perennials and annual species with long-lasting seed banks, may be buffered from population-level effects of herbivores (Maron \& Vilà 2001). Therefore, future studies should test whether enemy release and its effects on plant performance differ between growth forms.

As described in the Introduction, it is still not known whether invasive alien species closely related to native species are likely to incur more enemy impact than those distantly related. Our results indicate that neither relative damage nor relative performance of invasive alien over native species did depend on whether the species were congeneric or not. These results may suggest that enemy impact does not depend on taxonomic relatedness of invasive alien and native species. However, our analysis was limited by several factors. First, our study included a limited number of species, which were impacted by different types of enemies and under different environmental conditions. Second, relatedness of an invasive alien species to a native comparator is not necessarily representative of the relatedness of the invasive alien species to other species in the native plant community. Third, we used relatedness as a categorical variable (congeneric and non-congeneric) instead of as a continuous variable. Simply defining relatedness as either congeneric or non-congeneric may not give enough resolution to reflect ecological divergence, and misses the variation in phylogenetic relatedness of invaders to noncongeneric native species. Ideally, studies testing for the importance of relatedness of invasive species to native species should include more species, assess relatedness to the native community rather than the native comparator, and use phylogenetic relatedness or multiple taxonomic categories. Such studies are, however, still relatively rare (but see Dawson et al. 2009; Hill \& Kotanen 2009; Pearse \& Hipp 2009).

Whilst most studies have compared damage and/or performance between invasive alien and native species, the importance of enemy release for invasiveness can only be tested explicitly when we also assess damage and performance of non-invasive alien species. Few studies have compared enemy release (Mitchell \& Power 2003; van Kleunen \& Fischer 2009) or levels of enemy damage (Carpenter \& Cappuccino 2005; Liu et al. 2007; Parker \& Gilbert 2007; Ashton \& Lerdau 2008; Han et al. 2008; Jogesh et al. 2008) between alien species differing in invasiveness. Furthermore, because differences in individual plant performance do not necessarily translate into differences in population growth rates (Crawley 1989), we should test how the absence and presence of enemies affect population growth rates, by using, for example, demographic matrix models (Schutzenhofer et al. 2009).

The effect of enemy damage on plant performance is determined by the tolerance of species to damage. Therefore, tolerance could play an important role in linking enemy release to invasiveness. Surprisingly, however, few studies have investigated the role of tolerance to damage in plant invasions. Here, we propose to combine data on relative damage incurred by invasive alien and native species with data on shifts in relative performance of these species when grown in the absence and presence of enemies (Box 1). The few studies that provide such data suggest that frequently native species might be more tolerant to damage than invasive alien species, and that as a consequence invasive alien species might not capitalize on enemy release. However, more studies, assessing both damage levels and performance of invasive alien and native species in the absence and presence of enemies, are required to test whether this is a general pattern. To date, accumulated evidence suggests invasive alien species are as likely to be disadvantaged by natural enemies as they are to benefit from enemy release when compared to native species.

\section{ACKNOWLEDGEMENTS}

The authors thank J. Bascompte, E. Cleland and four anonymous referees for their helpful feedback on an earlier version of this paper. We are grateful to R.I. Colautti, F. Bretagnolle, D.C. Adams and J.L. Demizieux for constructive comments and discussions, and to P.M. Kotanen, A.A. Agrawal, K.A. Schierenbeck, I.W. Ashton, H. Dietz, M.R. Schutzenhofer, M.J. Lombardero, M.J.A. Vermeij and M.G. Park for providing data. YJC is thankful for support from the department of Santé des Plantes et Environnement at INRA. MvK and WD thank the 
National Centre of Competence in Research - Plant Survival for funding.

\section{REFERENCES}

Agrawal, A.A. \& Kotanen, P.M. (2003). Herbivores and the success of exotic plants: a phylogenetically controlled experiment. Ecol. Lett., 6, 712-715.

Agrawal, A.A., Kotanen, P.M., Mitchell, C.E., Power, A.G., Godsoe, W. \& Klironomos, J. (2005). Enemy release? An experiment with congeneric plant pairs and diverse above- and belowground enemies. Ecology, 86, 2979-2989.

Ashton, I.W. \& Lerdau, M.T. (2008). Tolerance to herbivory, and not resistance, may explain differential success of invasive, naturalized, and native North American temperate vines. Divers. Distrib., 14, 169-178.

Blaney, C.S. \& Kotanen, P.M. (2001). Effects of fungal pathogens on seeds of native and exotic plants: a test using congeneric pairs. J. Appl. Ecol., 38, 1104-1113.

Blumenthal, D.M. (2006). Interactions between resource availability and enemy release in plant invasion. Ecol. Lett., 9, 887895.

Brandt, A.J., Seabloom, E.W. \& Hosseini, P.R. (2009). Phylogeny and provenance affect plant-soil feedbacks in invaded California grasslands. Ecology, 90, 1063-1072.

Caño, L., Escarré, J., Vrieling, K. \& Sans, F.X. (2009). Palatability to a generalist herbivore, defence and growth of invasive and native Senecio species: testing the evolution of increased competitive ability hypothesis. Oecologia, 159, 95-106.

Carpenter, D. \& Cappuccino, N. (2005). Herbivory, time since introduction and the invasiveness of exotic plants. J. Ecol., 93, 315-321.

Colautti, R.I., Ricciardi, A., Grigorovich, I.A. \& MacIsaac, H.J. (2004). Is invasion success explained by the enemy release hypothesis? Ecol. Lett., 7, 721-733.

Crawley, M.J. (1989). Insect herbivores and plant population dynamics. Annu. Rev. Entomol., 34, 531-564.

Dawson, W., Burslem, D.F.R.P. \& Hulme, P.E. (2009). Herbivory is related to taxonomic isolation, but not to invasiveness of tropical alien plants. Divers. Distrib., 15, 141-147.

Elton, C.S. (1958). The Ecology of Invasions by Animals and Plants. Chapman and Hall, London, UK.

Hajek, A. (2004). Natural Enemies: An Introduction to Biological Control. Cambridge University Press, New York

Han, X., Dendy, S.P., Garrett, K.A., Fang, L. \& Smith, M.D. (2008). Comparison of damage to native and exotic tallgrass prairie plants by natural enemies. Plant Ecol., 198, 197210.

Hawkes, C.V. (2007). Are invaders moving targets? The generality and persistence of advantages in size, reproduction, and enemy release in invasive plant species with time since introduction. Am. Nat., 170, 832-843.

Hawkes, C.V., Douglas, A.E. \& Fitter, A.H. (2010). Origin, local experience, and the impact of biotic interactions on native and introduced Senecio species. Biol. Invasions, 12, 113-124.

Herms, D.A. \& Mattson, W.J. (1992). The dilemma of plants: to grow or defend. Q. Rev. Biol., 67, 283-335.

Hierro, J.L., Maron, J.L. \& Callaway, R.M. (2005). A biogeographical approach to plant invasions: the importance of studying exotics in their introduced and native range. J. Ecol., 93, 5-15.

Hill, S.B. \& Kotanen, P.M. (2009). Evidence that phylogenetically novel non-indigenous plants experience less herbivory. Oecologia, $161,581-590$.

Inderjit, Cadotte, M.W. \& Colautti, R.I. (2005). The ecology of biological invasions: past, present and future. In: Invasive Plants: Ecological and Agricultural Aspects (ed Inderjit). Birkhäuser Verlag, Basel, pp. 19-43.

Jogesh, T., Carpenter, D. \& Cappuccino, N. (2008). Herbivory on invasive exotic plants and their non-invasive relatives. Biol. Invasions, 10, 797-804.

Keane, R.M. \& Crawley, M.J. (2002). Exotic plant invasions and the enemy release hypothesis. Trends Ecol. Evol., 17, 164-170.

van Kleunen, M. \& Fischer, M. (2009). Release from foliar and floral fungal pathogen species does not explain the geographic spread of naturalized North American plants in Europe. J. Ecol., 97, 385-392.

van Kleunen, M., Weber, E. \& Fischer, M. (2010). A meta-analysis of trait differences between invasive and non-invasive plant species. Ecol. Lett., 13, 235-245.

Knapp, L.B., Fownes, J.H. \& Harrington, R.A. (2008). Variable effects of large mammal herbivory on three non-native vs. three native woody plants. Forest Ecol. Manag., 255, 92-98.

Lankau, R.A., Rogers, W.E. \& Siemann, E. (2004). Constraints on the utilization of the invasive Chinese tallow tree Sapium sebiferum by generalist native herbivores in coastal prairies. Eicol. Entomol., 29, 66-75.

Liu, H. \& Stiling, P. (2006). Testing the enemy release hypothesis: a review and meta-analysis. Biol. Invasions, 8, 1535-1545.

Liu, H., Stiling, P. \& Pemberton, R.W. (2007). Does enemy release matter for invasive plants? Evidence from a comparison of insect herbivore damage among invasive, non-invasive and native congeners. Biol. Invasions, 9, 773-781.

Louda, S.M. \& Potvin, M.A. (1995). Effect of inflorescence-feeding insects on the demography and lifetime fitness of a native plant. Eicology, 76, 229-245.

Mack, R.N. (1996). Predicting the identity and fate of plant invaders: emergent and emerging approaches. Biol. Conserv., 78, 107-121.

Maron, J.L. \& Vilà, M. (2001). When do herbivores affect plant invasion? Evidence for the natural enemies and biotic resistance hypothesis. Oikos, 95, 361-373.

Marquis, R.J. (1992). The selective impact of herbivores. In: Plant Resistance to Herbivores and Pathogens: Ecology, Evolution, and Genetics (eds Fritz, R.S. \& Simms, E.L.). University of Chicago Press, Chicago, pp. 301-325.

Mitchell, C.E. \& Power, A.G. (2003). Release of invasive plants from fungal and viral pathogens. Nature, 421, 625-627.

Mitchell, C.E., Agrawal, A.A., Bever, J.D., Gilbert, G.S., Hufbauer, R.A., Klironomos, J.N. et al. (2006). Biotic interactions and plant invasions. Ecol. Lett., 9, 726-740.

Müller-Schärer, H., Schaffner, U. \& Steinger, T. (2004). Evolution in invasive plants: implications for biological control. Trends Ecol. Evol., 19, 417-422.

Noble, I.R. \& Weiss, P.W. (1989). Movement and modelling of buried seed of the invasive perennial Chrysanthemoides monilifera in coastal dunes and biological control. Aust. J. Ecol., 14, 5564. 
Parker, I.M. (2000). Invasion dynamics of Cytisus scoparius: a matrix model approach. Ecol. Appl., 10, 726-743.

Parker, I.M. \& Gilbert, G.S. (2007). When there is no escape: the effects of natural enemies on native, invasive, and noninvasive plants. Ecology, 88, 1210-1224.

Parker, J.D., Burkepile, D.E. \& Hay, M.E. (2006). Response to Comment on 'Opposing effects of native and exotic herbivores on plant invasions'. Science, 313, 298b.

Pearse, I.S. \& Hipp, A.L. (2009). Phylogenetic and trait similarity to a native species predict herbivory on non-native oaks. Proc. Nath. Acad. Sci. USA, 106, 18097-18102.

Ricciardi, A. \& Ward, J.M. (2006). Comment on 'Opposing effects of native and exotic herbivores on plant invasions'. Science, 313, 298a.

Rosenberg, M.S., Adams, D.C. \& Gurevitch, J. (2000). MetaWin. Statistical Softivare for Meta-Analysis. Sinauer Associates, Sunderland, MA.

Sakai, A.K., Allendorf, F.W., Holt, J.S., Lodge, D.M., Molofsky, J., With, K.A. et al. (2001). The population biology of invasive species. Annu. Rev. Ecol. Evol. Syst., 32, 305-312.

Schutzenhofer, M.R., Valone, T.J. \& Knight, T.M. (2009). Herbivory and population dynamics of invasive and native Lespedera. Oecologia, 161, 57-66.

Siemann, E. \& Rogers, W.E. (2003). Herbivory, disease, recruitment limitation, and success of alien and native tree species. Ecology, 84, 1489-1505.

Stastny, M., Schaffner, U. \& Elle, E. (2005). Do vigour of introduced populations and escape from specialist herbivores contribute to invasiveness? J. Ecol., 93, 27-37.

Strauss, S.Y. \& Agrawal, A.A. (1999). The ecology and evolution of plant tolerance to herbivory. Trends Ecol. Evol., 14, 179-185.

\section{SUPPORTING INFORMATION}

Additional Supporting Information may be found in the online version of this article:

Appendix S1 Detailed methods of meta-analyses.

Appendix S2 Heterogeneity in effect sizes.

Appendix S3 Plant damage data set used in the meta-analyses.

Appendix S4 Plant performance data set used in the meta-analyses.

Appendix S5 Studies included in the meta-analyses. 